\title{
Gambaran Kematian Maternal di RSUP Dr. Hasan Sadikin Tahun 2019
}

\author{
Akhmad Yogi Pramatirta, Rizna Tyrani Rumanti \\ Departemen Obstetri dan Ginekologi Fakultas Kedokteran Universitas Padjadjaran/ \\ RSUP Dr. Hasan Sadikin \\ Korespondensi: Akhmad Yogi Pramatirta, Email: dryogipramatirta@yahoo.com
}

\begin{abstract}
Abstrak
Tujuan: Penelitian ini adalah untuk untuk memberikan gambaran mengenai kematian maternal yang terjadi di Rumah Sakit Hasan Sadikin tahun 2019

Metode: Subjek penelitian ini adalah seluruh kematian maternal selama bulan 2019 di Rumah Sakit Hasan Sadikin. Penelitian ini dilakukan dengan jenis penelitian deskriptif dan dengan rancangan penelitian cross sectional yaitu cara pendekatan, observasi atau pengumpulan data dimana pengumpulan data tersebut dilakukan pada saat yang bersamaan

Hasil: Karakteristik kematian maternal terbanyak adalah usia reproduksi $(88,8 \%)$, paritas terbanyak adalah multipara (58,3\%), berpendidikan cukup tinggi (94,5\%), seluruh pasien kematian maternal memiliki kontak antenatal dengan tenaga kesehatan $(100 \%)$ namun sebagian besar hanya melakukan kontak antenatal $<8$ kali $(74,4 \%)$, dan penyebab terbanyak dari kematian adalah hipertensi dalam kehamilan $(63,9 \%)$

Kesimpulan: Kematian maternal berkaitan dengan kontak antenatal yang kurang adekuat. Kontak antenatal yang tidak adekuat menyebabkan penanganan pasien dengan risiko tinggi menjadi kurang baik, terutama pasien dengan faktor risiko preeklampsia
\end{abstract}

Kata Kunci: Kematian maternal, kontak antenatal

\section{Description of Maternal Death in Dr. Hasan Sadikin General Hospital in 2019}

\begin{abstract}
Objective: The purpose of this study was to provide an overview of maternal deaths that occurred at Hasan Sadikin Hospital in 2019

Method: The subjects of this study were all maternal deaths during 2019 at Hasan Sadikin Hospital. This research was conducted with descriptive survey, cross sectional research design that is a way of approaching, observing or collecting data where the data collection was carried out at the same time

Results: The characteristics of the most maternal deaths are reproductive age (88.8\%), most parity is multiparaous (58.3\%), highly educated (94.5\%), all maternal death patients have antenatal care with health workers (100\%) but most only had antenatal care $<8$ times (74.4\%), and the most common cause of death was hypertension in pregnancy $(63.9 \%)$

Conclusion: Maternal deaths are associated with inadequate antenatal care. Inadequate antenatal care causes poor management of patients with high risk, especially patients with risk factors for preeclampsia
\end{abstract}

Keywords: Maternal death, antenatal care 


\section{Pendahuluan}

Angka Kematian Ibu adalah salah satu indikator penting dari derajat kesehatan masyarakat. Kematian ibu adalah kematian perempuan pada saat hamil atau kematian dalam kurun waktu 42 hari sejak terminasi kehamilan tanpa memandang lamanya kehamilan atau tempat persalinan, yakni kematian yang disebabkan karena kehamilannya atau pengelolaannya, tetapi bukan karena sebab-sebab lain seperti kecelakaan, terjatuh, dan lain-lain. Penghitungan angka kematian ibu adalah jumlah kematian selama periode tertentu per 100.000 kelahiran selama periode yang sama. ${ }^{1}$ Menurut survei angka sensus tahun 2015, angka kematian ibu di Indonesia saat ini berkisar 305 per 100.000 kelahiran. $^{2}$

Pelayanan kesehatan selama masa kehamilan, persalinan dan nifas sangat penting bagi keberlangsungan hidup ibu dan bayi, termasuk dalam upaya menurunkan angka kematian ibu dan bayi baru lahir. Pelayanan kesehatan ibu menjadi prioritas utama pembangunan kesehatan nasional maupun global. ${ }^{3}$

Ada beberapa faktor yang menjadi penyebab kematian ibu melahirkan, antara lain faktor reproduksi, komplikasi obstetrik seperti perdarahan, infeksi, serta faktor pelayanan kesehatan yang kurang baik. ${ }^{4}$ Kematian ibu berhubungan erat dengan akses pelayanan kesehatan berkualitas. Akses berkualitas akan memberikan kesempatan pada ibu untuk mendapatkan pemeriksaan kehamilan, pertolongan persalinan, dan pengobatan yang baik. ${ }^{5}$ Fokus percepatan untuk menurunkan AKI adalah dengan deteksi kehamilan risiko tinggi menggunakan sistem pendekatan risiko dan penanganan yang adekuat melalui sistem rujukan terencana. ${ }^{6}$

Kemampuan pengelolaan kasus rujukan kegawatan maternal pada rumah sakit dengan Pelayanan Obstetri Neonatal Emergensi Komprehensif (PONEK) mempengaruhi kematian maternal. Rumah Sakit Hasan Sadikin (RSHS) merupakan Rumah Sakit rujukan utama di Jawa Barat, termasuk rujukan kegawatan maternal. Kurangnya ketersediaan SDM (Dokter), sarana yang adekuat untuk pengelolaan kegawatan, serta metode atau prosedur pengelolaan rujukan yang tidak jelas menyebabkan rumah sakit tidak mampu mengelola kasus rujukan maternal, sehingga kematian maternal tidak dapat dihindari.

Penelitian ini dibuat untuk memberikan gambaran mengenai kematian maternal yang terjadi di Rumah Sakit Hasan Sadikin tahun 2019.

\section{Metode}

Penelitian ini dilakukan dengan jenis penelitian survei analitik dan dengan rancangan penelitian cross sectional yaitu cara pendekatan, observasi atau pengumpulan data dimana pengumpulan data tersebut dilakukan pada saat yang bersamaan.

\section{Hasil}

Selama tahun 2019 terdapat 3.140 kelahiran yang terjadi di RSHS (Gambar 1). Dari 3.140 kelahiran terdapat 36 kasus $(1,15 \%)$ kematian maternal (Gambar 2). Kematian terbanyak terjadi pada bulan Juni, yaitu sebanyak 7 kasus. Seluruh pasien merupakan kasus rujukan, domisili pasien sebagian besar berasal dari Bandung, sedangkan sisanya berasal dari luar Bandung (Gambar 3). Pasien yang berdomisili di Kota Bandung sebanyak 12 orang, yang berdomisili di Kabupaten Bandung sebanyak 8 orang, yang berdomisili di Kabupaten Bandung Barat sebanyak 6 orang. Sedangkan yang berasal dari luar Bandung adalah pasien yang berdomisili di Kabupaten Sumedang, Tasikmalaya, Cianjur, Sukabumi, Cilacap, Garut dan Subang. 


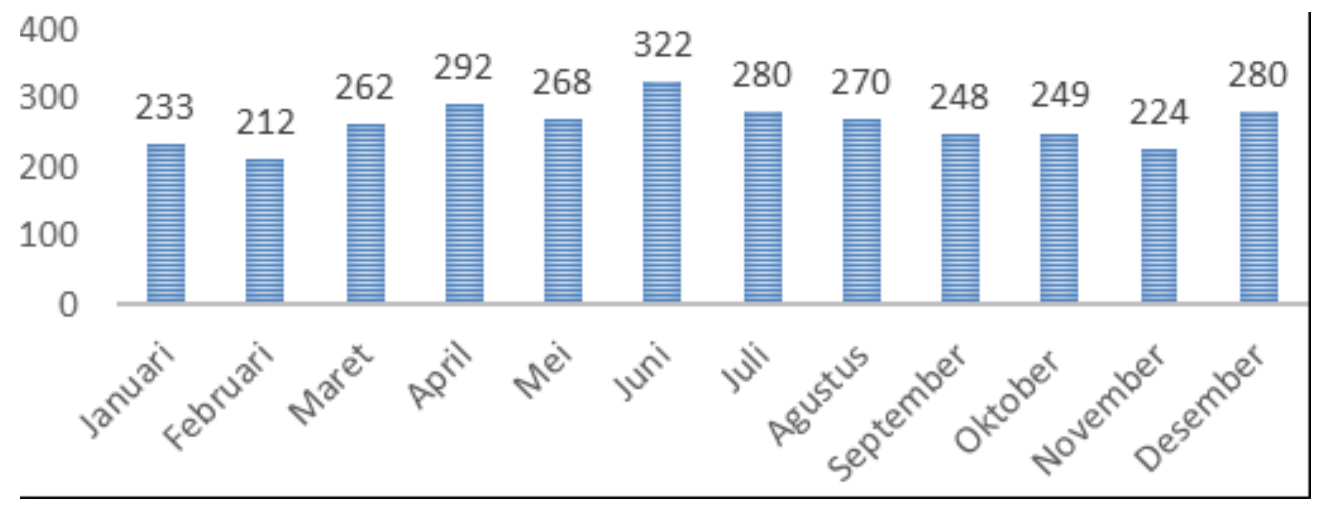

Gambar 1 Jumlah Persalinan di RSHS Tahun 2019

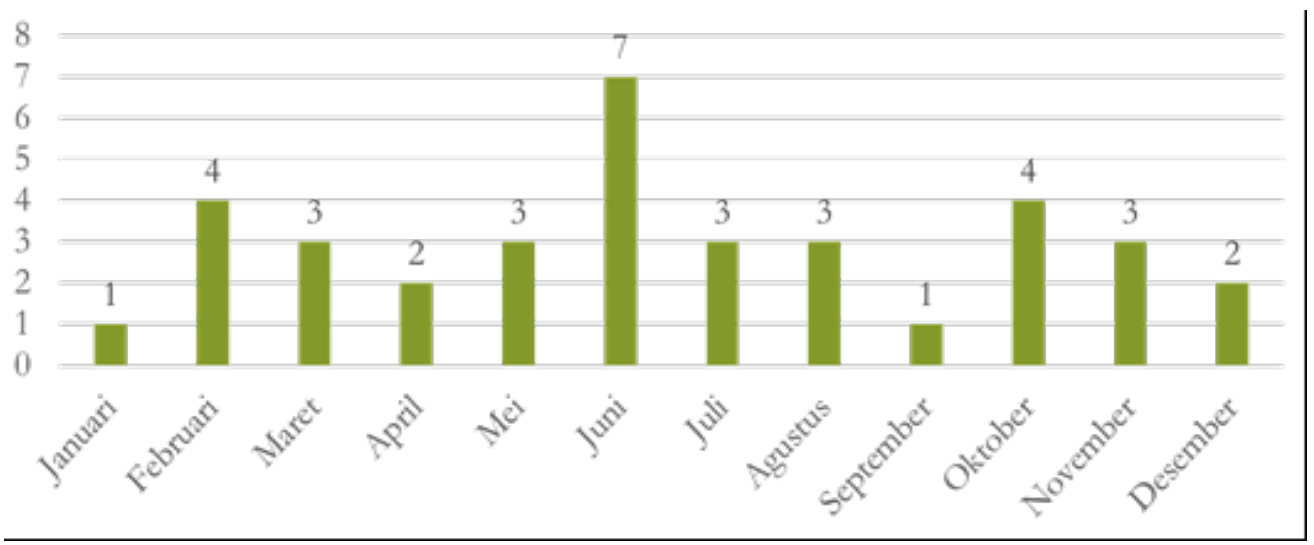

Gambar 2 Jumlah Kematian Maternal di RSHS Tahun 2019

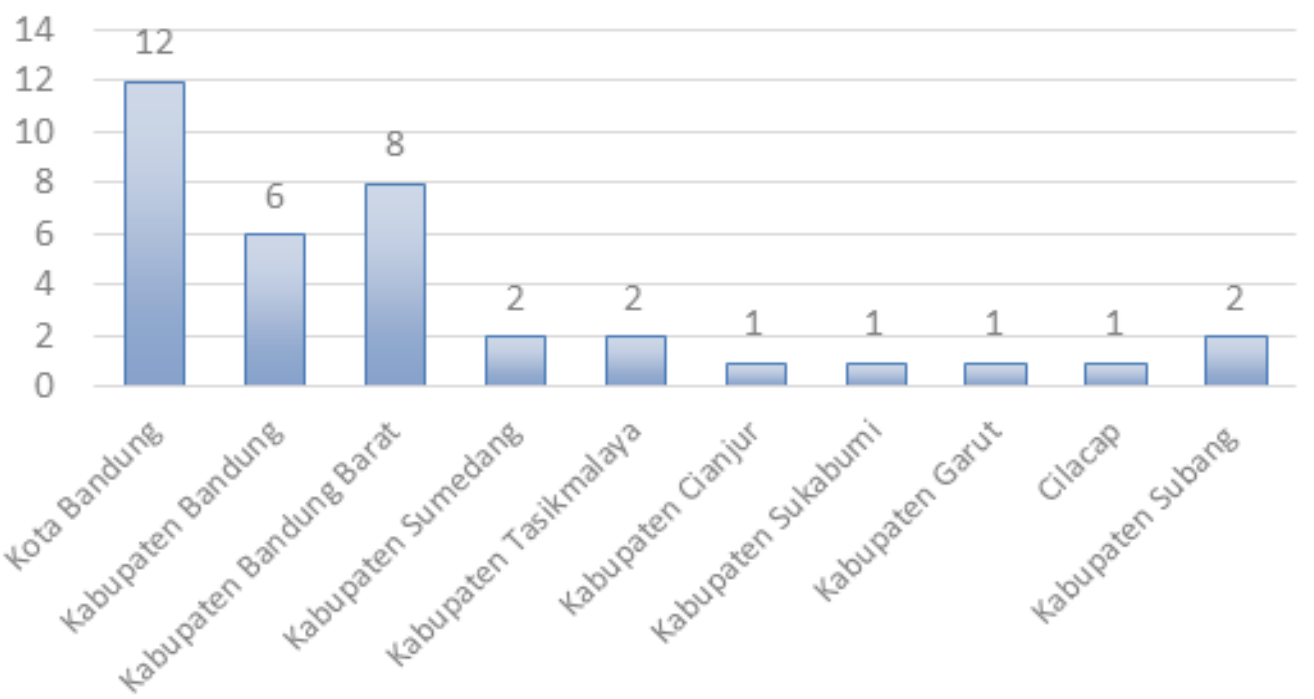

Gambar 3 Jumlah Kematian Maternal Berdasarkan Domisili di RSHS Tahun 2019 
Karakteristik kematian maternal (Tabel 1) berdasarkan usia adalah usia $<20$ tahun sebanyak 3 orang $(8,3 \%)$, usia $20-30$ tahun sebanyak 9 orang (25\%), usia 30-40 tahun sebanyak 23 orang $(63,8 \%)$ sedangkan usia $>40$ tahun sebanyak 1 orang $(2,7 \%)$.

Tabel 1 Karakteristik Kematian Maternal di RSHS tahun 2019

\begin{tabular}{lcc}
\hline Karakteristik & Jumlah & $\begin{array}{c}\text { Persentase } \\
(\%)\end{array}$ \\
\hline Usia & & \\
$<20$ tahun & 3 & 8,3 \\
20-30 tahun & 9 & 25 \\
30-40 tahun & 23 & 63,8 \\
$>40$ tahun & 1 & 2,7 \\
Paritas & & \\
Primipara & 8 & 22,2 \\
Multipara & 21 & 58,3 \\
Grande multipara & 7 & 19,4 \\
Tingkat & & \\
Pendidikan & & \\
SD & 2 & 5,5 \\
SMP & 7 & 19,4 \\
SMA & 19 & 52,7 \\
Diploma & 2 & 5,5 \\
Sarjana & 6 & 16,6 \\
\hline
\end{tabular}

Berdasarkan jumlah paritas, jumlah kematian maternal terbanyak adalah multipara yaitu sebanyak 21 orang (58,3\%). Primipara terdapat 8 orang $(22,2 \%)$ sedangkan grande multipara sebanyak 7 orang $(19,4 \%)$. Berdasarkan tingkat Pendidikan, jumlah kematian maternal adalah lulusan SMA yaitu 19 orang (52,7\%), disusul lulusan SMP sebanyak 7 orang $(19,4 \%)$, lulusan Sarjana sebanyak 6 orang $(16,6 \%)$, dan lulusan SD serta Diploma masing-masing sebanyak 2 orang $(5,5 \%)$. Berdasarkan kontak ante natal (Tabel 2), jumlah kematian maternal terbanyak datang ke bidan, yaitu sebanyak 16 orang (44\%), selebihnya datang ke spesialis kebidanan sebanyak 8 orang $(22,2 \%)$, ke spesialis kebidanan sekaligus bidan sebanyak 6 orang (16,7\%), ke Rumah Sakit sebanyak
2 orang $(5,6 \%)$ dan ke Puskesmas sebanyak 4 orang $(11,1 \%)$. Berdasarkan jumlah kunjungan kontak ante natal, 27 orang $(74,4 \%)$ melaksanakan kontak ante natal kurang dari 8 kali, hanya 9 orang $(25,6 \%)$ yang melaksanakan kontak ante natal sebanyak 8 kali atau lebih.

\section{Tabel 2 Jumlah Kematian Maternal Berdasarkan Kontak Ante Natal di RSHS tahun 2019}

\begin{tabular}{lcc}
\hline \multicolumn{1}{c}{ Kontak } & Jumlah & $\begin{array}{c}\text { Persentase } \\
\text { Ante Natal }\end{array}$ \\
\hline Spesialis Kebidanan & 8 & 22,2 \\
Bidan & 16 & 44,4 \\
Spesialis Kebidanan & 6 & 16,7 \\
dan Bidan & & \\
Rumah sakit & 2 & 5,6 \\
Puskesmas & 4 & 11,1 \\
\hline
\end{tabular}

Berdasarkan waktu kematian sebanyak 28 pasien $(77,8 \%)$ meninggal setelah melahirkan, sedangkan sebanyak 8 orang $(22,2 \%)$ meninggal sebelum melahirkan. Berdasarkan tempat kematian, kematian maternal terbanyak terjadi di ruang perawatan yaitu sebanyak 16 pasien $(52,7 \%)$, sedangkan pasien lain terjadi di ruang ICU/ CICU sebanyak 13 pasien $(36,1 \%)$, di ruang emergensi/ruang resusitasi dan ruang bersalin/ruang operasi masing-masing sebanyak 2 orang $(5,6 \%)$.

Penyebab kematian terbanyak adalah hipertensi dalam kehamilan, yaitu 23 pasien $(63,9 \%)$, kemudian diikuti perdarahan post partum sebanyak 9 pasien $(25,6 \%)$ dan lainlain sebanyak 4 pasien $(11,1 \%)$. Berdasarkan kebutuhan intubasi, sebanyak 12 pasien $(33,3 \%)$ meninggal dengan menggunakan ventilator dan sebanyak 5 pasien $(13,8 \%)$ meninggal dengan ventilasi meninggal. Berdasarkan jumlah leukosit, sebanyak 21 pasien $(58,3 \%)$ menunjukkan leukositosis sedangkan sebanyak 4 orang pasien $(11,1 \%)$ memiliki leukopenia. 
Tabel 3 Jumlah Kematian Maternal Berdasarkan Penyebab Kematian di RSHS Tahun 2019

\begin{tabular}{|c|c|c|}
\hline $\begin{array}{l}\text { Penyebab } \\
\text { Kematian }\end{array}$ & Jumlah & $\begin{array}{c}\text { Persentase } \\
(\%)\end{array}$ \\
\hline $\begin{array}{l}\text { Hipertensi } \\
\text { dalam kehamilan }\end{array}$ & (23) & $(63,9)$ \\
\hline $\begin{array}{l}\text { Respiratory } \\
\text { failure }\end{array}$ & 13 & 36,1 \\
\hline - Cardiac failure & 10 & 27,8 \\
\hline $\begin{array}{l}\text { Perdarahan post } \\
\text { partum }\end{array}$ & 9 & 25,6 \\
\hline Lain-lain & 4 & 11,1 \\
\hline
\end{tabular}

\section{Pembahasan}

Karakteristik kematian maternal berdasarkan usia sebagian besar $(88,8 \%)$ usia produktif namun masih pula dijumpai sebagian kecil yang berusia resiko tinggi. Grande multipara berhubungan erat dengan tingginya angka kematian maternal, kematian maternal tahun 2019 terdapat grande multipara sebanyak 7 orang $(19,4 \%)$. Berdasarkan tingkat pendidikan hanya 2 orang $(5,5 \%)$ yang lulusan SD, sebanyak 34 orang $(94,5 \%)$ pendidikan di atas SMP, hal ini menunjukkan sebagian besar kematian maternal terjadi pada ibu dengan pendidikan cukup tinggi, seharusnya kesadaran akan risiko tinggi kehamilan lebih baik. ${ }^{7}$

Seluruh pasien kematian maternal memiliki kontak antenatal dengan tenaga kesehatan. Tenaga kesehatan yang paling banyak memberikan pelayanan pemeriksaan kehamilan adalah bidan yaitu sebanyak 16 pasien $(44,4 \%)$, diikuti oleh dokter kandungan sebanyak 8 pasien $(22,2 \%)$. Hal ini menunjukkan bahwa bidan masih berperan penting dalam pelayanan pemeriksaan kehamilan.

Pedoman

WHO terbaru merekomendasikan jumlah kontak yang dimiliki wanita hamil dengan penyedia layanan kesehatan selama kehamilannya ditingkatkan dari empat menjadi delapan. Bukti terbaru menunjukkan bahwa frekuensi yang lebih tinggi dari kontak antenatal oleh wanita dengan penyedia layanan kesehatan dikaitkan dengan penurunan kemungkinan kelahiran mati. Ini karena meningkatnya peluang untuk mendeteksi dan mengelola potensi komplikasi. ${ }^{8}$ Jumlah kematian maternal sebagian besar hanya melakukan kontak antenatal $<8$, yaitu sebanyak 27 orang $(74,4 \%)$. Hal ini menyebabkan komplikasi kehamilan tidak terdeteksi lebih dini.

Trias utama kematian ibu adalah perdarahan, hipertensi dalam kehamilan (HDK) dan infeksi. Profil Kesehatan Indonesia Tahun 2014, hampir 30\% kematian ibu di Indonesia pada tahun 2010 disebabkan oleh HDK. Penyebab kematian terbanyak di RSHS pada tahun 2019 adalah hipertensi dalam kehamilan, yaitu 23 pasien $(63,9 \%)$. Insiden preeklampsia di Indonesia sendiri adalah 128.273/tahun atau sekitar 5,3\%. Kecenderungan yang ada dalam dua dekade terakhir ini tidak terlihat adanya penurunan yang nyata terhadap insiden preeklampsia, berbeda dengan insiden infeksi yang semakin menurun sesuai dengan perkembangan temuan antibiotik..$^{9} 10$

Simpulan, berdasarkan hasil penelitian, disimpulkan bahwa karakteristik kematian maternal terbanyak adalah usia reproduksi $(88,8 \%)$, paritas terbanyak adalah multipara (58,3\%), berpendidikan cukup tinggi $(94,5 \%)$, seluruh pasien kematian maternal memiliki kontak antenatal dengan tenaga kesehatan $(100 \%)$ namun sebagian besar hanya melakukan kontak antenatal $<8(74,4 \%)$, dan penyebab terbanyak dari kematian adalah hipertensi dalam kehamilan $(63,9 \%)$.

Diharapkan agar ibu yang mempunyai faktor risiko agar rutin memeriksakan kehamilan sehingga angka kematian dapat berkurang dan bagi para pemberian asuhan agar lebih sigap dalam menangani pasien dengan risiko tinggi, terutama pasien dengan faktor risiko preeklampsia. 


\section{Daftar Pustaka}

1. Riskesdas. Hasil Utama Riskesdas Penyakit Tidak Menular 2018. Has Utama Riskesdas Penyakit Tidak Menular. 2018;

2. Direktorat Kesmas. Di Rakesnas 2019, Dirjen Kesmas Paparkan Strategi Penurunan AKI dan Neonatal [Internet]. Kemenkes RI. 2019 [cited 2020 Jun 12]. Available from: www.kesmas.kemkes. go.id/portal/konten/ rilis-berita/021517di-rakesnas-2019_-dirjen-kesmaspaparkan-strategi-penurunan-aki-danneonatal\%0D

3. Kemenkes RI. Survey Demografi dan Kesehatan Indonesia. Survei Demografi dan Kesehatan Indonesia 2017. 2017.

4. Firani NK. Hubungan Antara Tingkat Pendidikan Ibu Hamil Dengan Perilaku Ibu Dalam Memilih Penolong Persalinan. EGALITA. 2012;

5. Irianto J, Suharjo S. The Contribution of Public Health Center to Reducing Maternal Mortality. Bul Penelit Sist Kesehat. 2016;

6. Diflayzer D, S.A. S, Nofita E. Gambaran Faktor Risiko Kegawatdaruratan Obstetri pada Ibu Bersalin yang Masuk di Bagian Obstetri dan Ginekologi RSUD Dr. Rasidin Padang Tahun 2014. J Kesehat Andalas. 2018;

7. Nuraisya W. Deteksi Risiko Tinggi Kehamilan Pada Pelayanan ANC Terpadu di Puskesmas Bendo Kabupaten Kediri. J Kesehat Andalas. 2018;

8. WHO. WHO | New guidelines on antenatal care for a positive pregnancy experience. Who. 2016.

9. Asmana SK, Yahredi, Hilbertina N. Hubungan Usia dan Paritas dengan Kejadian Preeklampsia Berat di Rumah Sakit Achmad Mochtar Bukittinggi Tahun. J Kesehat Andalas. 2016;
10. Lo JO, Mission JF, Caughey AB. Hypertensive disease of pregnancy and maternal mortality. Current Opinion in Obstetrics and Gynecology. 2013. 